\title{
La construcción del yo-lírico y el nihilismo. Concepciones barrocas y la filosofía de Kierkegaard en Nostalgia de la muerte de Villaurrutia.
}

\section{The construction of lyric-self and nihilism. Baroque notions and} Kierkegaard's philosophy in Nostalgia de la muerte by Villaurrutia.

DOI: $10.32870 /$ sincronia.axxv.n80.4b21

\author{
Herwig Weber \\ Universidad del Claustro de Sor Juana. (MÉXICO) \\ CE: hweber@elclaustro.edu.mx / ID ORCID: 0000-0002-8794-7736
}

Esta obra está bajo una Licencia Creative Commons Atribución-NoComercial 4.0 Internacional

Recibido: $10 / 02 / 2021$

Revisado: 30/04/2021

Aprobado: 25/05/2021

\section{RESUMEN}

El presente trabajo es una interpretación de Nostalgia de la muerte de Xavier Villaurrutia a partir de conceptos filosóficos interconectados del barroco, idealismo y nihilismo, que conciben al sujeto (yo-lírico) encerrado en sí mismo, sin posibilidad o necesidad de entrar en contacto con el exterior. Estos conceptos ven amenazada la integridad del sujeto y plantean su reconstrucción sin consideración del mundo externo. La obra del poeta mexicano está influenciada por los motivos del horror vacui (Pascal) y de la mónada (Leibniz), y muestra concordancias con la idea del sujeto como absoluto y como nada (Hegel) así como con la constitución dialéctica que plantea Kierkegaard.

Palabras clave: Literatura comparada. Poesía mexicana del siglo XX. Literatura comparada. Constitución de sujeto. Filosofía barroca. Nihilismo. 


\section{ABSTRACT}

The present work is an interpretation of Nostalgia de la Muerte by Xavier Villaurrutia based on some interconnected philosophical concepts from the Baroque, Idealism and Nihilism, notions that conceive the subject (lyrical ego) as locked in itself, without the possibility or the need of coming into contact with the outside. These notions threaten the integrity of the subject and support its reconstruction regardless of the outside world. The work of the mexican poet is influenced by the concepts of horror vacui (Pascal) and the monad (Leibniz); it shows affinity with the idea of the subject as an absolute and as nothing (Hegel), and with the dialectical constitution of the subject in times of nihilism (Kierkegaard).

Keywords: Comparative literature. Mexican poetry of the 20th century. Constitution of the subject. Barroque philosophy. Nihilism.

Eine der philosophisch gefährlichsten Ideen ist, merkwürdigerweise, daß wir mit dem Kopf oder im Kopf denken. Die Idee vom Denken als einem Vorgang im Kopf, in dem gänzlich abgeschlossenen

Raum, gibt ihm etwas Okkultes. Ludwig Wittgenstein $\left(1967\right.$, p.105) ${ }^{1}$

La historia cultural narra el desarrollo del sujeto como una extensión de su interioridad. Una razón para el retiro del individuo a su propio interior es que, con la modernidad, el exterior se considera cada vez más contingente y, por lo tanto, amenazante. Sin embargo, la contingencia del exterior surgió, paradójicamente, gracias a su objetivación, por la cual el mundo se volvió extraño para el sujeto $^{2}$. El pensamiento positivista acabó con todas las narraciones del mundo de las cosas. Por ello, Octavio Paz subraya que, en la Edad Moderna, "la extrañeza deja de ser un extravío y se vuelve ejemplar" (Paz, 1990, p.10). Nostalgia de la muerte de Xavier Villaurrutia se puede interpretar como

\footnotetext{
1 "Una de las ideas filosóficas más peligrosas es, curiosamente, que pensamos con la cabeza o en la cabeza. La idea del pensamiento como un proceso en la cabeza, en un espacio completamente encerrado, contiene algo ocultista." (Todas las traducciones de los proverbios son del autor del artículo).

${ }^{2}$ En la historia cultural de la evolución de la conciencia de Jean Gebser, la modernidad —o la época mental, como él la nombra - está caracterizada por la oposición de un sujeto interno a un mundo externo. El filósofo suizo estableció tres épocas anteriores a esta época mental: arcaica, mágica y mítica (Gebser, 2011, pp.71-172), en las cuales aún no se puede hablar de un sujeto o el sujeto aún no se encuentra en una oposición directa con el exterior
} 
el punto final de este desarrollo: Todo es interior. Para el sujeto, para el yo-lírico, el exterior del mundo de las cosas está completamente abolido, pues se trata de un mundo sin sentido. Este texto literario parece ser, en una primera lectura, el resultado del desarrollo del pensamiento moderno, en el que el reductio scientiae ad mathematicam distinguió al sujeto del objeto, expulsó el mito narrativo y, al mismo tiempo, el significado del mundo. La realidad exterior se volvió irreal para el humano, por eso, el mundo le parece cada vez más y más un sueño ?un motivo literario y filosófico recurrente a partir del barroco.

Pero en un mundo carente de significado, el hombre tampoco se reconoce a sí mismo y ya no es capaz de constituirse como sujeto. Así, también el sujeto mismo, no solo el exterior, se volvió extraño por su objetivación, por "la reificación de todas las relaciones entre los individuos" (Adorno, 1990, p.43) ${ }^{3}$. Una consecuencia del pensamiento económico, biológico-positivista y lingüístico es, entonces, el cuestionamiento de la idea de que el sujeto es una unidad metafísica estable. ${ }^{4}$ A este estado de duda se le nombra nihilismo.

También en Nostalgia de la muerte está presente dicho proceso de devaluación del significado del exterior seguido por la devaluación de la identidad del yo: Según Ramón Xirau, este sigue, en la obra de Villaurrutia, al desprendimiento de los objetos del mundo, "la experiencia de un total desarraigo de la conciencia misma, de una despersonalización radical” (Xirau, 1955, p.32). El carácter fragmentario de la antología de poemas que conforma Nostalgia de la muerte subraya la pérdida de unidad e identidad de un sentido; metáfora para la pérdida de identidad y unidad del

\footnotetext{
3 “[...] die Verdinglichung aller Beziehungen zwischen den Individuen [...]" (La traducción al español es del autor del artículo).

${ }^{4}$ Este es uno de los principales argumentos en el libro de Michel Foucault Las palabras y las cosas. Foucault nombra los tres discursos del siglo XIX que crean al hombre y al sujeto, el discurso biológico, lingüístico y económico: "Cuando la historia natural se convierte en biología, cuando el análisis de la riqueza se convierte en economía, cuando, sobre todo, la reflexión sobre el lenguaje se hace filología y se borra este discurso clásico en el que el ser y la representación encontraban su lugar común, entonces en el movimiento profundo de tal mutación arqueológica, aparece el hombre con su posición ambigua de objeto de un saber y de sujeto que conoce [...]" (Foucault, 1968, pp.303-304). Estos discursos científicos amenazan al hombre y al sujeto con la extinción: "Todos estos contenidos que su saber revela como exteriores a él y más viejos que su nacimiento, lo anticipan, desploman sobre él toda su solidez y lo atraviesan como si no fuera más que un objeto natural o un rostro que ha de borrarse en la historia" (Foucault, 1968, p.305).
} 
sujeto expresado. Pero al mismo tiempo — como se verá a continuación - se constituye al sujeto a partir de un mecanismo dialéctico y se afirma a partir del concepto del miedo a la nada y la muerte.

La interpretación literaria es la simulación de la búsqueda de un sentido original. Y cada texto poético remite a una significación filosófica. "[L]a esencia de la poesía descansa en el pensar", opina Heidegger (2001, p.210). Para un acercamiento a este sentido original, las relaciones entre los conceptos literarios y filosóficos tienen que ser demostradas o ser plausibles. El presente ensayo tiene como finalidad describir los antecedentes filosóficos de Nostalgia de la muerte, del concepto de la interioridad total y de la crisis del sujeto en un entorno nihilista.

Se ha afirmado en varios análisis la importancia del barroco para Villaurrutia, la influencia de la poesía del Siglo de Oro se muestra en la construcción de los poemas, el hermetismo de los temas, la abundancia de imágenes, las metáforas sublimes, la característica y el uso de los adjetivos (Palma, 2001) y, sobre todo, en el motivo de la "poesía como única realidad en el sueño de la existencia" (Millares, 1996, p.1046). A pesar de que existen numerosos estudios sobre Nostalgia de la muerte, todavía no se ha abordado su relación con el concepto de la mónada barroca. En este trabajo se analizará el motivo del sujeto encerrado en sí mismo (como una mónada) al que le es imposible llegar a un conocimiento de sí mismo y del mundo que lo rodea. Este tema que también se podría nombrar existencialista, es evidente en Nostalgia de la muerte, pero este artículo busca, además, construir una conexión con la filosofía del fundador del pensamiento existencial, con Kierkegaard.

El propósito de este trabajo no consiste, en primera instancia, en demostrar una influencia —el resultado es especulativo-, sino en añadir a las interpretaciones de Nostalgia de la muerte una lectura a partir del concepto kierkegaardiano de espiritualidad o inwardness ${ }^{5}$ y de su concepto dialéctico de la constitución del sujeto. Algunas alusiones a la filosofía de Hegel sirven como un puente entre la filosofía del barroco y la de Kierkegaard. Las referencias al pie de página a textos de Rilke, mediador entre el pensador danés y Villaurrutia, completarán la reconstrucción de esta red intertextual.

${ }^{5}$ El traductor, filósofo y teólogo existencialista Theodor Haecker usa la palabra Innerlichkeit (inwardness) para caracterizar la filosofía de Kierkegaard (Haecker, 1913). 


\section{Conceptos barrocos en Nostalgia de la muerte de Xavier Villaurrutia}

La noche en los "Nocturnos" es el tiempo metafórico que significa la ausencia de significado e identidad. En la oscuridad y en el silencio, el yo-lírico permanece solo con el espacio vacío. No hay cosas visibles. El sujeto se da cuenta de dicho vacío existencial en la noche, pues esta lo arroja sobre sí mismo. La reclusión crea en el yo-lírico la sensación de una "inmersión en las profundidades de un desconocido océano" (Moretta, 1976, p.48), en la vacuidad del vasto océano del exterior y, al mismo tiempo, en el profundo océano de la propia alma. El entrelazamiento del sujeto (yo-lírico) y el entorno (mar) proviene de la filosofía y lírica barrocas; la expresión idónea de esta relación es el oxímoron poético. El oxímoron, la hipérbole y el hipérbaton son también expresión de lo irracional del pensamiento de que haya algo (el sujeto) que está rodeado por la nada (el mundo de los objetos) y por eso es también nada (Palma, 2001, p.127).

Que Villaurrutia comparte la fascinación del barroco por este tema y por las figuras retóricas mencionadas, se muestra en el epígrafe de Michael Drayton (1563-1631) en Nostalgia de la muerte: "Burned in a sea of ice and drowned amidst a fire" (Villaurrutia, 1974, p.265). ${ }^{6}$ Se trata de un fragmento del soneto LXII de Idea del autor inglés. En la introducción de este ciclo de sonetos se puede leer: "My verse is the true image of my mind" (Drayton, 1908, p.67). ${ }^{7} \mathrm{Y}$ el primer soneto comienza con la descripción de una odisea: "LIKE an adventurous seafarer am I, / Who hath some long and dangerous voyage been" (Drayton, 1908, p.68). ${ }^{8}$

Las figuras oximorónicas y dialécticas en Nostalgia de la muerte son las siguientes: La noche se asocia con el conocimiento, ella "hace oír" (p.44) y a la vez se expresa mediante la metáfora de la ceguera la imposibilidad de conocer: "no es la noche sino la ceguera / lo que llena de sombra nuestros ojos" (p.52). El miedo del yo-lírico a la nada es omnipresente, aunque, al mismo tiempo le da la bienvenida a la nada de la noche, al "placer que revela" (Villaurrutia, 1974, p.44). La voz-lírica

\footnotetext{
6 "Quemado en un océano de hielo y ahogado en fuego". (La traducción al español de esta y de las siguentes dos citas son del autor del artículo).

7 "Mi poema es la verdadera imagen de mi mente".

8 "Soy como un marinero aventurero / que tuvo un viaje largo y peligroso".
} 
se describe como independiente del yo-lírico, pero esta voz está simultáneamente cautivada dentro del yo:

$$
\begin{gathered}
\text { Tengo miedo de mi voz } \\
\text { y busco mi sombra en vano. } \\
\text { ¿Será mía aquella sombra } \\
\text { sin cuerpo que va pasando? } \\
\text { ¿Y mía la voz perdida } \\
\text { que va la calle incendiando? }
\end{gathered}
$$

Otra figura temática oximorónica es que el yo-lírico se pierde en la noche de los "Nocturnos" como en un mar enorme; al mismo tiempo, el interior del sujeto consta de este mar vacío.

\section{El alma perdida en un amplio espacio}

O und die Nacht, die Nacht, wenn der Wind voller Weltraum uns am Angesicht zehrt [...].

$$
\text { Rainer Maria Rilke (1991, p.441) }
$$

Un alma ha naufragado en su propio interior, como las almas barrocas en los Sueños (1627) de Quevedo, las Soledades (1613) de Góngora o en la poesía de Sor Juana (Millares, 1996, p.1044). El mar dentro del cual ha naufragado el sujeto es, como lo expresa Octavio Paz, "un espacio sin nombres ni límites" (Paz, 1989, p.471). El espacio no tiene nombre porque el mundo de las cosas ya no se comunica con los humanos, como ya se ha mencionado antes. Esta distancia de las cosas

\footnotetext{
9 "Oh y la noche, la noche, cuando el viento lleno del espacio universal consume nuestro rostro [...]."
} 
encuentra su expresión, en Villaurrutia, en la desesperación del humano porque las estrellas ya no le hablan:

[C]uando en la soledad de un cielo muerto

brillan unas estrellas olvidadas

y es tan grande el silencio

que de pronto quisiéramos que hablara.

(Villaurrutia, 1974, p.51)

La referencia a las estrellas es un tópico clásico de la cultura antigua. Las estrellas aún les hablaban a los pensadores griegos. Pitágoras responde a la pregunta del significado de su vida con una referencia al estudio de los cielos. Al reproche de descuidar a su familia y su tierra natal, Anaxágoras se defiende mediante la referencia a los cuerpos celestes: "Ahí está mi hogar" (Jäger, 1942, p.49). Incluso a finales de la Edad Media y en el Renacimiento, la conexión del hombre con el universo sigue estando intacta. Dante recibe de su maestro Brunetto Latini en el infierno de la Divina Comedia (1321) el consejo de seguir a sus estrellas, "así llegarás al puerto de la fama" (Alighieri, 1994, p.68). Marsilio Ficino pide al lector en su Libro sobre el sol y la luz (1494) elevar su mirada al cielo creado por Dios con un orden estricto y dejarse "narrar" la historia de este orden por las relaciones celestiales (Ficino, 1999, p.5). Desde la antigüedad existe la idea, "que la estructura del universo está ordenada por la armonía [...], que hay una música cuyos modos son los elementos" (Steiner, 2013, p.62).

El mundo aparece como un cosmos, como una "comunidad de cosas" (Jäger, 1942, p.159) sujeta al orden y la justicia. La racionalización del pensamiento occidental comienza con la lectura e interpretación de la naturaleza de este cosmos. La meteorología es la ciencia de la exégesis de las cosas, tanto externas como en las alturas. ${ }^{10}$ Cuando el destino del hombre está en las estrellas, el hombre solo tiene que leerlas con suficiente atención para conocer su futuro. A partir de esta lectura, la lógica exterior penetra en el interior del hombre, se crea la lógica del interior a partir de

10 “¿Qué arte, qué método, qué práctica nos sube a donde debemos encaminarnos? [...] He aquí, pues, los destinados a la subida: el filósofo nato, el músico, el enamoradizo" (Plotino, 1982, p.225). 
la interpretación del exterior. Pero con la creación del hombre racional, el concepto de verdad universal también toma fuerza y la verdad de lo externo desvanece. La decepción, expresada por Villaurrutia, de que las cosas ya no "hablan" con el sujeto, de que se suprime la correspondencia de la lógica del exterior y del interior, es, como ya se mencionó, un rasgo característico de la modernidad.

Con el espacio sin fronteras surge el horror y la fascinación del ser humano barroco ante un nuevo concepto de lo infinito. Pero este infinito no solo describe la macrodimensión del espacio externo, sino también la microdimensión de la profundidad de la conciencia humana. El sujeto moderno se encuentra perdido en estas dos dimensiones. Francisco de Quevedo ha acuñado para esta pérdida en el infinito la metáfora de la "Ilama flotante en el agua fría" (Quevedo, 1948, p.814). Según el matemático y filósofo francés Blaise Pascal, "todas las cosas han salido de la nada y van llevadas hasta el infinito" (Pascal, 1967, p.23), por eso "bogamos en un vasto medio, siempre inciertos y flotantes, empujados de un extremo al otro" (p.25). ${ }^{11}$ En Nostalgia de la muerte se expresa de la misma manera el vacío y el silencio de un espacio eterno y la ausencia del desarrollo de acciones o pensamientos. En el poema "Nocturno solo", el yo-lírico se refiere al vacío de este espacio con "líquida sombra en que me hundo / vacío del pensamiento" (Villaurrutia, 1974, p.50). En "Nocturno miedo", el mundo le parece al yo-lírico sombras "de una calle desierta [...] lívido espejo de la soledad" (p.45). "Nocturno en que nada se oye" evoca las impresiones de la soledad infinita en una ciudad abandonada, una "soledad sin paredes" (p.47).

\footnotetext{
11 "Nous voguons sur un milieu vaste, toujours incertains et ottants, poussés d'un bout vers l'autre" (Pascal, 1897, p.17). Villaurrutia tuvo contacto con el pensamiento de Pascal mediante, por ejemplo, el ensayo del escritor francés Jean Prévost "Faltas de cálculo de apuesta de Pascal". Lo menciona en su artículo "Ensayistas franceses contemporáneos" (Villaurrutia, 1974, p.694).
} 


\section{El alma, una mónada}

[D]ie Seele .... ist ein weites Land Arthur Schnitzler (1962, p.280) ${ }^{12}$

Para Pascal, el infinito no solo se extiende hacia afuera, hacia lo infinitamente grande del universo visible, sino también hacia adentro, hacia lo infinitamente pequeño del universo invisible. En el fragmento 72 de sus Pensées (1897) expresa un estremecimiento ante el silencio eterno de estos espacios infinitos y luego agrega que el hombre no es capaz de comprender ni la nada de la que vino ni el infinito en el que está sumergido. Y dado que todas las cosas nacieron de la nada y conducen al infinito, probablemente siguen siendo un misterio ?lo cual significa el comienzo de la desconfianza en la percepción. Cuando, a partir de Galilei y Newton, la matemática empieza a dominar todas las técnicas de adquisición del conocimiento, la brecha entre la percepción sensible y la percepción racional del entorno se agranda cada vez más. Como consecuencia de dicho proceso, el sujeto se separa más y más del entorno material, pues ya no confía en sus sentidos; su razón "se ve siempre decepcionada por la inconstancia de las apariencias" (Pascal, 1967, p.25). ${ }^{13}$

La desconfianza en la percepción y la fascinación por lo infinito se expresa, en la filosofía del barroco, con el concepto de la mónada - que en la antigüedad también sirvió para representar lo absoluto mediante la imagen de un punto dentro de un círculo (Imagen 1)—. En él, también está presente el motivo anteriormente descrito del yo que se encuentra sumergido en un océano infinito que es su propio interior - motivo que, como se ha visto, es de gran importancia en Nostalgia de la muerte- La mónada no solo se puede describir como un mundo: cada conciencia es una mónada

\footnotetext{
12 "[E]l alma ... es un amplio espacio".

${ }^{13}$ Respecto a la desconfianza de lo percibido sensiblemente y respecto al encierro del humano en su propio interior véase, por ejemplo, Arendt (2002, pp. 252-257) o Heisenberg (1955, pp.17): “Anstatt mit objektiven Eigenschaften [...] finden wir uns mit den von uns selbst erbauten Apparaten konfrontiert, und anstatt der Natur oder dem Universum begegnen wir gewissermaßen immer nur uns selbst."; "En lugar de estar confrontados por propiedades objetivas, nos encontramos confrontados por los aparatos que hemos construido, y en lugar de la naturaleza o el universo, nos encontramos, por así decirlo, solo a nosotros mismos." (La traducción es del autor de este artículo.)
} 
-cada conciencia es algo absoluto-.${ }^{14}$ Leibniz se imagina esa conciencia como una narración infinita contada por Dios y regida por la lógica de pasos infinitamente pequeños de causas y efectos. La mónada como conciencia no necesita ni ventana ni puerta para poder comunicarse con el exterior (Leibniz 2001, p.106) porque contiene toda la narración del mundo, incluyendo a todas las otras mónadas: "El mundo está envuelto en cada sujeto y no existe más que envuelto en cada sujeto" (Deleuze, 2006, p.152). Por tanto, se puede interpretar al yo-lírico de Nostalgia de la muerte como una mónada barroca cerrada en sí misma, pues en el exterior no hay nada. Por eso, Octavio Paz nombra a la poesía de Villaurrutia "una poesía solitaria y para solitarios" (1986, p.3).

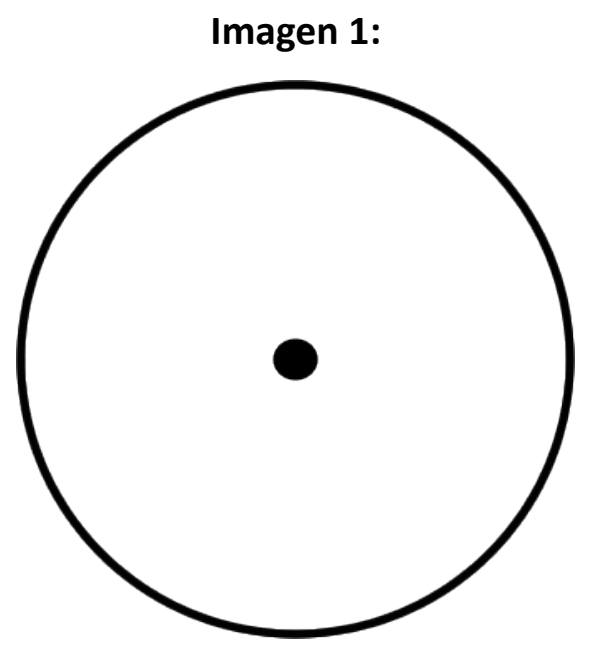

El punto dentro de un círculo — símbolo de la mónada como lo absoluto en la antigüedad-

Fuente: Creación propia

Pero también el mundo interno del sujeto encerrado en sí mismo es contingente. La contradicción de que el impulso de buscar verdades es inherente al humano, aunque este sepa que no se puede llegar a ninguna idea clara de nada, es expresada por Pascal de la siguiente manera:

Si damos con un término a que pensamos vincularnos y en que pensamos afianzarnos, titubea y nos abandona; y si lo seguimos, se nos escapa de las manos, se desliza y nos huye

14 “[T]odas las sustancias simples o Mónadas creadas podrían llamarse Almas [...]" (Leibniz, 2001, p.110). 
con una fuga eterna. Nada se detiene por nosotros. Es el estado que nos es natural, y, sin embargo, el más contrario a nuestra inclinación; ardemos en deseos de encontrar una sede firme y una última base constante [...] (Pascal 1967, p.25).

El escepticismo hacia un conocimiento acertado y seguro está presente también en Nostalgia de la muerte: en "Nocturno de una estatua", el yo-lírico busca la fuente de un grito, pero nunca la encuentra ?lo que siempre hay son "solo" sombras de verdades, la verdad misma se esconde detrás de ecos, muros y espejos:

Correr hacia la estatua y encontrar solo el grito, querer tocar el grito y solo hallar el eco, querer asir el eco y encontrar solo el muro y correr hacia el muro y tocar un espejo.

(Villaurrutia, 1974, pp.46-47)

La vida sin ninguna solidez reconocible o una base constante tiene que parecer al humano -que depende de su estabilidad - algo irracional y como un sueño.

\section{La vida es un sueño}

[E]l hombre que vive sueña lo que es hasta despertar. Calderón de la Barca (1989, p.98)

El motivo más obvio que retoma Villaurrutia de la poesía barroca es el de la vida como un sueño y el de la muerte como la vida verdadera. El Macbeth shakespeareano se queja - confrontado por la muerte de su señora- del carácter sombrío de la vida con las siguientes palabras:

Life's but a walking shadow, a poor player

That struts and frets his hour upon the stage 
And then is heard no more. It is a tale

Told by an idiot, full of sound and fury, Signifying nothing. (Shakespeare, 1925, p.1124). ${ }^{15}$

Y poetas como Hugo von Hofmannsthal, Rainer Maria Rilke o Los contemporáneos transportaron esta metáfora de la vida como sueño del barroco (de Calderón de la Barca p.ej.) al siglo XX. ${ }^{16} \mathrm{El}$ motivo barroco de la realidad sombría se encuentra en la repetición de la palabra "sombra" en los primeros tres poemas de Nostalgia de la muerte. En los primeros dos ("Nocturno" y "Nocturno miedo") aparece dos veces, en el tercero (“Nocturno grito") cuatro veces. El yo-lírico de "Nocturno de la estatua" sueña todas las cosas del mundo que le rodea: "la noche, la calle, la escalera" (Villaurrutia 1974, p.46). Pero no solo sueña el mundo, un sueño que "quiere escapar" de la frente del yo-lírico del poema "Nocturno preso", sino también él mismo es soñado por otro. ${ }^{17}$ Estos otros que sueñan a los yo-líricos son nombrados ángeles en el "Nocturno" con el mismo nombre. Cuando duermen esos seres, que vuelan "a ras de tierra", "sueñan no con los ángeles sino con los mortales" (Villaurrutia 1974, p.57).

En el poema "Nocturno miedo", Villaurrutia evoca - mediante varias figuras oximorónicas idóneas para la temática - la imagen de los sonámbulos y de la gruta del sueño para desenmascarar la vida como un sueño y la muerte como un despertar:

Entonces, con el paso de un dormido despierto,

Sin rumbo y sin objeto nos echamos a andar.

La noche vierte sobre nosotros su misterio,

\footnotetext{
15 "La vida es solo una sombra caminante, un mal actor / que se pavonea en el escenario / y después ya no se escucha nada. Es un cuento de hadas narrado por un idiota, lleno de ruido y furia, / que no significa nada" (La traducción es del autor del artículo).

${ }^{16}$ El drama La torre (Der Turm, 1928) de Von Hofmannsthal es una adaptación de La vida es sueño. En la primera parte de los Sonetos a Orfeo (Sonette an Orpheus, 1922) de Rilke se encuentran cuatro estrofas que tratan de una niña que duerme en el oído del yo-lírico y sueña el mundo exterior de este (Rilke, 1991b, pp.487-488).

${ }^{17}$ La idea villaurrutiana de que el sueño del yo-lírico quiere ser libre o que ya está suelto del yo, anticipa llamativamente la teoría de los discursos de la postmodernidad antes mencionados en referencia a Foucault. Los discursos son narraciones que atraviesan el sujeto y lo constituyen, pero como son independientes del sujeto, este solo es como un sueño de otra entidad (lingüística).
} 
$\mathrm{Y}$ algo nos dice que morir es despertar.

(Villaurrutia, 1974, p.45)

Para la filosofía barroca, la noche y el sueño son de gran importancia en cuanto a la posibilidad que representan de alcanzar el conocimiento. Muchas veces el sueño, el pequeño hermano de la muerte, es el despertar a la verdad.

El joven René Descartes tuvo, una noche de 1619, tres sueños que definieron su camino. Dejó atrás todas sus creencias y su futura filosofía estuvo basada en el contenido de estos sueños. En uno de ellos, Descartes sueña que despierta y que de sus ojos salen rayos de fuego que le permiten ver claramente las cosas a su alrededor.

Una noche de 1654, Pascal encontró su verdad. La noche le entregó un conocimiento que no depende ni de la percepción empírica ni de la razón no-empírica. La oscuridad pura reveló la luz pura, la verdad pura -como en el caso de Descartes- a través del "fuego": La verdad de la grandeza de Dios y de la "grandeza del alma humana". Dicha verdad nocturna no pudo ser proclamada en un texto filosófico-científico; el filósofo francés la anotó en un cuasipoema, en su Memorial (Imagen 2). 


\section{Imagen 2}

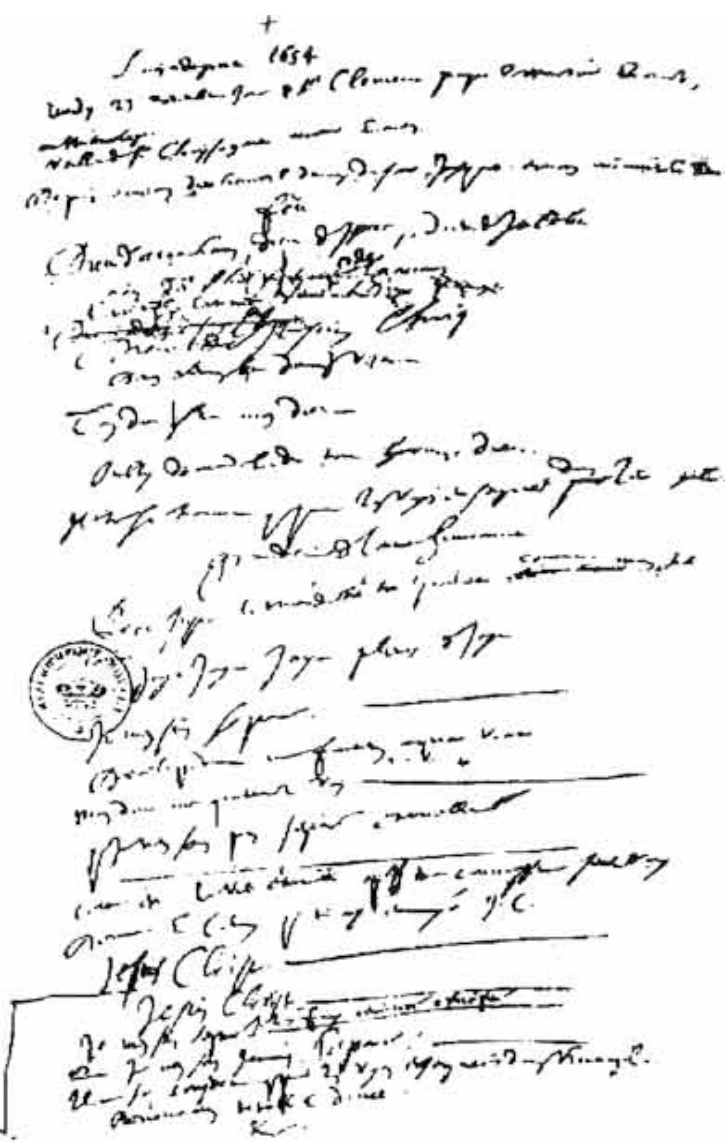

El Memorial de Blaise Pascal

Fuente: Oeuvres de Blaise Pascal (Ed. Léon Brunschvicg)

El descubrimiento poético de que la vida es un exilio y que la nada, que está representada por la muerte, es la patria verdadera, se encuentra expresada en "Volver", uno de los poemas más concisos y citados en Nostalgia de la muerte. Como lo expresó Pascal, la muerte - que es la nadasignifica el principio absoluto del ser; por tanto, al morir, el sujeto regresa a este principio absoluto, a su patria: "Volver a una patria lejana [...] La nada es mi patria lejana” (Villaurrutia, 1974, pp.69-70). 
La realidad de la vida es, entonces, nada más que una sombra, solo un sueño. Pero ya no es la sombra de los objetos de la vida real o de las ideas platónicas, sino la sombra más oscura de la nada.

Como la muerte es más real que la vida, "toma siempre la forma de la alcoba / que nos contiene" (Villaurrutia, 1974, p.60). En el barroco surgió la pregunta, ¿cómo es posible una interacción entre los sujetos que son concebidos como mónadas?, ¿cómo interactúa la mente humana con el aspecto material del mundo ${ }^{18}$ Para Leibniz, por ejemplo, Dios es el mediador entre las mónadas. ${ }^{19}$ En tiempos de nihilismo, la respuesta tiene que ser otra. Villaurrutia contesta poéticamente: como la muerte es más real que la vida, esta -y no el amor o Dios o los dos, el amor dei- es la base, la ley de la posibilidad de las relaciones entre sujetos:

Entonces, solo entonces, los dos solos, sabemos

que no el amor sino la oscura muerte

nos precipita a vernos cara a cara a los ojos,

y a unirnos y estrecharnos, más que solos y náufragos,

todavía más y cada vez más, todavía

(Villaurrutia, 1974, p.61).

La muerte unifica porque no distingue, es "oscura", y posibilita la interacción entre humanos en una vida que es un sueño. Si la verdadera vida es la muerte, en esa vida todo es igual y está unificado. Todos los infinitos de esa esfera de la muerte son iguales, como diría Pascal (1967, p.25): No hay distinciones en particularidades. Y la sombra de esta ley sobre el mundo falso es el axioma que permite la conexión entre las mónadas individuales que son los sujetos.

\footnotetext{
18 'L'homme est à luimême le plus prodigieux objet de la nature; car il ne peut concevoir ce que c'est que corps, et encore moins ce que c'est qu'esprit, et moins qu'aucune chose comme un corps peut être uni avec un esprit" (Pascal 1897, p.19);“El hombre es, para sí mismo, el más prodigioso objeto de la naturaleza, porque no puede concebir lo que es ser cuerpo, menos aún lo que es ser espíritu y, menos que cualquier otra cosa, cómo un cuerpo puede estar unido con un espíritu" (Pascal, 1967, p.23).

19 "Pero en las sustancias simples el influjo de una Mónada en otra es solo ideal, el cual no puede producir su efecto más que mediante la intervención de Dios, en tanto que, en las ideas de Dios, una Mónada postula, con razón, que Dios, al regular las restantes desde el comienzo de las cosas, la tenga en cuenta. Pues, como una Mónada creada no puede influir físicamente en el interior de otra, no hay otro medio sino éste por el que la una pueda depender de otra" (Leibniz, 2001, p.120).
} 
El motivo oximorónico de la vida como sueño y de la muerte como vida real posiciona, como se ha visto, al interior transcendental del sujeto como la única verdad ontológica. La realidad del exterior está prácticamente abolida por este motivo.

\section{Idealismo, interioridad y la nada}

En el curso de los tiempos modernos, la verdad se encuentra, entonces, cada vez más en el interior. Para Immanuel Kant, el carácter de las cosas no era comprensible, pero la impresión obtenida a través de los sentidos era aún importante, ya que, sin ella, las categorías de la razón pura no tendrían sentido.

El siglo XIX, el siglo del nihilismo, está dedicado al prolongado desarrollo del interior. Georg Wilhelm Friedrich Hegel estuvo influenciado en su descripción del sujeto por la Monadología de Leibniz (Horn, 1965). Pero para el filósofo idealista, el ser absoluto, que es al mismo tiempo el sujeto, no es exclusivamente una dialéctica sino también, en última consecuencia, la nada. ${ }^{20}$ Por eso, la oscuridad de la noche en la obra de Villaurrutia no solo significa la ausencia de todo en un sentido común, sino también en un sentido dialéctico. Según Hegel, tanto la oscuridad absoluta como la luz absoluta significan el vacío. Solo una mezcla de oscuridad y luz permite ver. ${ }^{21}$ Pero en la

\footnotetext{
${ }^{20}$ En la Enciclopedia de las ciencias filosóficas en compendio, Hegel escribe lo siguiente: “§ 86 [...] Si ser se expresa como predicado de lo absoluto, obtenemos así la primera definición de éste: Lo absoluto es el ser. [...] § 87 Ahora bien, ese ser puro es la pura abstracción y por tanto lo absolutamente negativo que, tomado igualmente de la manera inmediata, es la nada; de hecho, tal definición se implica cuando se dice que la cosa-en-sí es lo indeterminado, lo que simplemente carece de forma y contenido [...]" (Hegel, 2005, p. 189). "§ 86 [...] Wird Sein als Prädikat des Absoluten ausgesagt, so gibt dies die erste Definition desselben: Das Absolute ist das Sein. [...] $\S 87$ Dieses reine Sein ist nun die reine Abstraktion, damit das Absolut-Negative, welches, gleichfalls unmittelbar genommen, das Nichts ist. 1. Es folgte hieraus die zweite Definition des Absoluten, dass es das Nichts ist; in der Tat ist sie darin enthalten, wenn gesagt wird, dass das Ding an sich das Unbestimmte, schlechthin Form- und damit Inhaltslose ist, [...]" (Hegel, 1979, pp.182-183).

21 "La pura luz y la pura oscuridad son dos vacíos que son la misma cosa. Solo en la luz determinada - y la luz se halla determinada por medio de la oscuridad-, y por lo tanto solo en la luz enturbiada, puede distinguirse algo; así como solo en la oscuridad determinada - y la oscuridad se halla determinada por medio de la luz- y por lo tanto en la oscuridad aclarada [es posible distinguir algo], porque solo la luz enturbiada y la oscuridad aclarada tienen en sí mismas la distinción y por lo tanto son un ser determinado, una existencia [concreta]" (Hegel, 1982, pp.120-121). Original: "Reines Licht und reine Finsternis sind zwei Leeren, welche dasselbe sind. Erst in dem bestimmten Lichte - und das Licht wird durch die Finsternis bestimmt -, also im getrübten Lichte, ebenso erst in der bestimmten Finsternis - und die Finsternis wird durch das Licht bestimmt -, in der erhellten Finsternis kann etwas unterschieden werden, weil erst das
} 
noche de la oscuridad completa, el yo-lírico de la obra de Villaurrutia empieza a ver de una forma diferente. Ve sin ojos. Entiende en la oscuridad absoluta de la noche, en "Nocturno en que habla la muerte", que el principio de todo ser es la nada: "Nada es el mar", "nada es la tierra”, "[n]ada son estas cosas" (Villaurrutia, 1974, p.54). Según el principio de la dialéctica, mediante estas reflexiones sobre la nada se crea algo. Algo interno. Se crea el sujeto transcendental del yo-lírico.

Hegel vio en la subjetividad, en la estructura de la autorreferencia, el "principio del nuevo tiempo" (Habermas, 1985, p.17). Para el filósofo, la interioridad era el "principio protestante" (Hegel, 1979, p.120). El camino hacia adentro también está conectado íntimamente con el protestantismo: Con la propagación de la lectura de cada individuo a través de la tipografía, cada vez menos personas necesitan de las otras para comunicar, pues interactúan solo con su propio interior: "Leer (latín: legere) siempre ha significado en su etimología medieval intus legere: Leer en el interior, en el corazón." ${ }^{22}$ Es sobre todo Hegel quién destaca, mediante la referencia a Descartes, el principio de la interioridad como el axioma de la filosofía moderna per se.

Este pensamiento, que es para sí, esta cúspide más pura de la interioridad, se afirma y hace fuerza como tal, relegando a segundo plano y rechazando como ilegítima la exterioridad muerta de la autoridad. Solo el pensamiento libre que en mí se alberga puede reconocer y corroborar, como tribunal competente, el pensamiento. Lo cual tiene, a la par, el sentido de que este pensamiento constituye una misión general del mundo y de los individuos, más aún, el deber de cada cual, ya que todo se basa en él; de tal modo que lo que en el mundo pasa por algo firme e inconmovible, tiene que ser considerado así por el pensamiento del hombre, para que se lo reconozca como tal (Hegel, 1955, p.252). ${ }^{23}$

getrübte Licht und die erhellte Finsternis den Unterschied an ihnen selbst haben und damit bestimmtes Sein, Dasein sind“ (Hegel, 1999, p.55).

22 "Lesen (lat. legere) hat in seiner mittelalterlichen Etymologie immer schon intus legere bedeutet: im Innersten, im Herzen lesen." (Haas, 2011, p.107). (La traducción es del autor de este artículo).

${ }^{23}$ Original: "Das allgemeine Prinzip ist jetzt, die Innerlichkeit als solche festzuhalten, die tote Äußerlichkeit als Autorität zurückzusetzen, für ungehörig anzusehen. Nach diesem Prinzip der Innerlichkeit ist nun das Denken, das Denken für sich, die reinste Spitze des Innersten, diese Innerlichkeit das, was sich für sich jetzt aufstellt; und dies Prinzip fängt mit Descartes an. Es ist das Denken frei für sich, was gelten soll, was anerkannt werden soll; dies kann es nur durch mein freies Denken in mir, nur dadurch kann es mir bewährt werden. Dies hat zugleich den Sinn, dass dies Denken allgemeines Geschäft, Prinzip für die Welt und die Individuen ist: das, was gelten, was festgesetzt sein soll in der Welt, 
Como destaca Octavio Paz, Villaurrutia tenía conocimientos de las doctrinas sobre el arte de Hegel y Kant. A pesar de la desconfianza del poeta mexicano ante los sistemas filosóficos ?desconfianza que comparte con Kierkegaard??, leyó el ensayo de Benedetto Croce, Lo vivo y lo muerto de la filosofía de Hegel de 1907 (Paz, 2003, p.44). ${ }^{24}$ En este estudio, Croce destaca la importancia de los opuestos para el sistema del filósofo alemán, en el cual la síntesis de estos no es una ilusión, sino que caracteriza un movimiento, un desarrollo. Para Hegel, la verdad no es el ser ni la nada, sino el desaparecer del uno en el otro ?el devenir. Toda la realidad es desarrollo, que Hegel nombra "historia". Solo se puede hablar de espíritu dentro de su desarrollo histórico. Fuera de él es nada. Para Hegel, la autoconciencia es un resultado temporal de la dialéctica entre independencia y sujeción. El ego siempre se forma a través del reconocimiento de los otros, dependiendo de algo opuesto. $^{25}$ En Nostalgia de la muerte está presente la dialéctica hegeliana, esa constante dualidad de la autoconciencia. Por un lado, el yo-lírico reconoce que todo es nada, incluso su propia subjetividad. Tal nihilismo es una metáfora de la independencia hegeliana. Por el otro lado, con este reconocimiento y con la escritura de los poemas de Nostalgia de la muerte se forma un sujeto, el yo-lírico. Esto hace referencia a la dependencia hegeliana. La formación de ese yo-lírico en el texto poético es entonces un constante proceso dialéctico que divaga entre los polos independencia y dependencia ?un alumno de Hegel, Søren Kierkegaard retoma este concepto.

muss der Mensch durch seine Gedanken einsehen; was für etwas Festes gelten soll, muss sich bewähren durch das Denken“ (Hegel, 1979, p.120).

${ }^{24}$ Sin embargo, Octavio Paz reitera también que la influencia que recibió Villaurrutia de la lectura sobre las teorías de Hegel fue superficial.

${ }^{25}$ Véase el capítulo "Independencia y sujeción de la autoconciencia, señorío y servidumbre" en la Fenomenología del espiritu (Hegel, 1966, pp.113-120). 


\section{Kierkegaard y Villaurrutia: filósofo y poeta de la interioridad en tiempos del nihilismo}

Kierkegaard no es el filósofo predilecto de Xavier Villaurrutia. ${ }^{26}$ Pero a través del poeta Rainer Maria Rilke como "mediador", es posible trazar una conexión entre el filósofo danés y el poeta mexicano ?ly esta conexión tiene que ver con la idea de la constitución dialéctica del sujeto en los tiempos del nihilismo. La relación literaria de la obra de Villaurrutia con la de Rilke está claramente demostrada (Vasconcelos, 1994). ${ }^{27}$ Y Rilke a su vez, estaba muy influenciado por los textos de Kierkegaard. ${ }^{28}$ El poeta praguense destaca sobre todo su concepto de inwardness, que fue utilizado para describir a un humano "verdaderamente interno" (Rilke, 1950, p.33).

Kierkegaard -en conexión, sobre todo, con el idealismo de Hegel- vinculó su concepto de existencia con la idea del pensador subjetivo: "La reflexión de la interioridad es la doble reflexión del pensador subjetivo. Pensando, piensa lo general, pero en cuanto existiendo en este pensamiento y adquiriéndolo en su interioridad se aísla cada vez más en su subjetividad" (Kierkegaard, 2010, p.82).

\footnotetext{
${ }^{26}$ Ese filósofo es Martin Heidegger. Octavio Paz menciona la relación de Villaurrutia con los textos del pensador alemán (Paz, 2003, p.68). Para un análisis de la influencia de Heidegger en la obra del poeta mexicano véase H. Weber, 2019, pp. 205-214.

${ }^{27}$ El poeta mexicano escribió un breve ensayo sobre la obra del praguense. En este describe el encuentro con Los apuntes de Malte Laurids Brigge (1910) de Rilke como uno "definitivo, imborrable y no superado después de la lectura de cuantas obras de Rilke [...]" (Villaurrutia, 1974, p.949). Octavio Paz destaca las diferencias entre los dos poetas respeto al tema de la muerte: "Del poeta alemán procede casi seguramente la idea de la "muerte propia", pero la concepción rilkeana de la muerte es muy distinta a la de Villaurrutia. Para Xavier -latino, católico y mexicano- la muerte no era pretexto de vuelos metafísicos sino motivo de recogimiento y aceptación. A pesar de su amor por las letras francesas, su tradición era la hispánica, a un tiempo estoica y cristiana: la muerte es el fin de esta vida y, para los cristianos, el salto hacia la otra, la eterna. Heredero del neorromanticismo y del simbolismo, Rilke se enfrenta a la muerte pero no para aceptarla a la estoica ni para trascenderla a la cristiana sino para transformarla. La muerte no es un límite ni un tránsito sino una abertura [sic]; con ella y en ella comienza la gran metamorfosis que nos lleva a la unidad: la vida y la muerte son las dos caras de la misma realidad" (Paz, 2003, p.67).

${ }^{28}$ Como confiesa en una carta a Ilse Erdmann: "[L]eerlo es morar en él, es pathos, voz y paisaje solitario, un reclamo infinito del corazón, un dictado, un trueno y un silencio, como la quietud de las flores [...]. Original: "[l]hn lesen heisst in ihm wohnen, er ist Pathos, Stimme und einsame Landschaft, ein unendlicher Anspruch ans Herz, ein Diktat, ein Donner und eine Stille, wie die Stille der Blumen [...]" (Rilke, 1950, p.33). La relación dolorosa de Kierkegaard con Regine Olsen es para Rilke el punto de partida para su teoría de los no-amados que se encuentra tanto en Los apuntes de Malte Laurids Brigge como en las Elegias de Duino. Respecto a la relación de Rilke con los textos de Kierkegaard, véase también Lisi (2013) y Cardinal (1969).
} 
Para Kierkegaard, la verdad es "no material" (Adorno, 1979, p.60). Al flâneur danés la realidad le aparece "solo reflejada por la mera interioridad" (Adorno, 1979, p.62). El mundo real (externo) se ha vuelto tan extraño que los autores en la primera mitad del siglo XX crean "un espacio interno" para "evitar al sujeto un paso falso" (Adorno, 1990, p.44). ${ }^{29}$ El naufragio está preprogramado en el interior cuando las cosas ya no le hablan al hombre, cuando el alma sufre un naufragio en el espacio silencioso de lo externo. El nihilismo de su época y el vacío de todos los valores externos e internos se manifiesta, para Kierkegaard, en el concepto de lo público y en la praxis de los medios masivos de comunicación - un análisis también muy profético, si se piensa en las tendencias más recientes de las redes de comunicación. A este proceso de aniquilación de lo individual para volverse público, el filósofo danés lo nombró "levelling": "Levelling at its maximum is like the stillness of death, where one can hear one's own heartbeat, a stillness like death, into which nothing can penetrate, in which everything sinks, powerless" (Kierkegaard, 1962, p.51). Nostalgia de la muerte se puede interpretar, sin duda, como la expresión poética del último estado de este proceso de aniquilación de todos los valores, del momento de inmovilidad total, de la situación sin ninguna esperanza en el progreso humanista ? ? estado que, en el siglo XX, fue la base de la teoría existencialista.

\section{El concepto del miedo}

Ich habe etwas getan gegen die Furcht. Ich habe die ganze Nacht gesessen und geschrieben [...]. Rainer Maria Rilke (1991c, p.121) ${ }^{30}$

\footnotetext{
${ }^{29}$ El interior del protagonista danés [i!] en la novela Los apuntes de Malte Laurids Brigge es tan extenso que abarca todo el mundo (del texto). "Ich habe ein Inneres, von dem ich nicht wußte. Alles geht jetzt dorthin", apunta Malte al respecto (Rilke, 1991c, pp. 110-111): "Tengo un interior que no he conocido. Todo se direcciona ahora hasta allá." (La traducción es del autor del artículo).

30 "Hice algo contra el miedo. Me senté toda la noche y escribí [...]".
} 
La temática existencialista es más notoria en la primera parte de Nostalgia de la muerte, en los "Nocturnos". Villaurrutia traza en ellos "un itinerario de disolución del ente, entendido como lo que permanece y perdura, hasta concluir en el silencio, hasta volver con la palabra imposible la palabra" (Maldonado, 2010, p.101). En el "Nocturno miedo", la preocupación existencial de no ser nada se expresa a través de la angustia de ser solo un cuerpo vacío:

\section{El miedo de no ser sino un cuerpo vacío}

que alguien, yo mismo o cualquier otro, puede ocupar,

y la angustia de verse fuera de sí, viviendo,

y la duda de ser o no ser realidad (Villaurrutia, 1974, pp.45-46).

El interior del yo-lírico está formado, sobre todo, por la percepción de este vacío del espacio y también se encuentra amenazado por él. La noche en los "Nocturnos" es el tiempo-lugar que es posible interpretar como una metáfora para la ausencia de sentido, progreso o identidad. ${ }^{31}$ En el barroco, la lógica de la mónada (Leibniz) o la fe en dios (Pascal) rescata al sujeto de la amenaza del vacío. Y en el siglo del nihilismo, Kierkegaard se imagina la constitución de subjetividad de la siguiente forma:

La posición del yo-lírico de Nostalgia de la muerte cambia, no solo respecto al tema de la muerte, sino también respecto al motivo del miedo: Ya no es el miedo que surge de la inseguridad relacionada con el significado de la muerte para la existencia. El yo-lírico ahora teme a la nada como un principio dominante de la vida. Kierkegaard describe la vida como una enfermedad que consiste en el miedo ante la muerte que, en tiempos nihilistas, significa la disolución del individuo en la nada. ${ }^{32}$ El yo-lírico de Nostalgia de la muerte se ve amenazado por esa gran nada y esta amenaza encuentra su expresión en el miedo.

\footnotetext{
31 También el sujeto Malte Laurids Brigge, en su exilio París, consta de sensaciones de un espacio sin mueblario significativo, y sus reflexiones y autorreflexiones tratan de la muerte, que en tiempos del nihilismo está asociada con ninguna cualidad "personal".

32 "If in the strictest sense we are to speak of a sickness unto death, it must be one in which the last thing is death, and death the last thing. And this precisely is despair" (Kierkegaard, 1941, p.24)
} 
Pero para Kierkegaard, este miedo es al mismo tiempo una expresión del yo del hombre. Es la única prueba posible de su libre albedrío y por lo tanto de su libertad, como lo describe en El concepto del miedo (Begrebet Angest, 1844). Aquí y en La enfermedad mortal (Sygdommen til Døden, 1849), Kierkegaard concibe el ser del individuo como un devenir, como un proceso dinámico (Patios, 2013). Ya que el sujeto está determinado por su libre albedrío y el miedo es la expresión de este sujeto que tiene frente a sí un futuro de libres decisiones, esta secuencia de decisiones libres es su esencia. Y la secuencia de decisiones libres se puede nombrar historia. El hombre está hecho de historia y, al mismo tiempo, crea esta historia. ${ }^{33}$ Para Kierkegaard, la autoconciencia no significa la autoobservación -Husserl y Sartre estarán más tarde, por diferentes razones, de acuerdo con esto- y devenir y no ser es la categoría ontológica prevaleciente. La autoconciencia solo puede constar de la acción. ${ }^{34}$ "Ser un yo" significa, según Kierkegaard, la creación de dicho yo a través del tiempo. Con esto, el humano crea al mismo tiempo su historia (Patios, 2013, p.45) y, en un sentido más amplio y conectado con la noción de la cultura, el concepto de historia en general.

Solo donde el futuro - que es el tiempo más importante para Kierkegaard- está lleno de elecciones libres junto con sus consecuencias, se encuentra el temor, signo del alma según el filósofo danés. Incluso si la razón de la ansiedad del yo-lírico de Nostalgia de la muerte no está directamente relacionada con las decisiones sobre su futuro, sino con la sospecha de que todo, incluido su yo, no es nada, se constituye y se revela, así, un sujeto. En esta interpretación kierkegaardiana del texto de Villaurrutia es precisamente el miedo a la nada el que "puede ocupar", como lo expresa el filósofo danés, el que expresa algo, el que expresa el alma.

Si el comienzo de Nostalgia de la muerte está determinado por el miedo a la nada y la muerte, entonces este temor en sí mismo es una prueba de la individualidad del sujeto. Con tal certeza, el miedo pierde su estado real y se transforma en anhelo debido al esfuerzo intelectual. El

\footnotetext{
33 En Los apuntes de Malte Laurids Brigge se muestra la conexión entre subjetividad e historia en la forma de las anotaciones que componen la novela: Es un viaje al pasado mítico de la humanidad.

34 "This self-consciousness is not contemplation, for he who believes this has not understood himself, because he sees that meanwhile he himself is in the process of becoming and consequently cannot be something completed for contemplation. This self-consciousness, therefore, is action"(Kierkegaard, 1980, p.143). Kierkegaard insiste mucho en la praxis, lo que parece ser una rebelión, igual a la de Marx, contra el teórico Hegel.
} 
yo-lírico de Nostalgia de la muerte también llega a la comprensión racional de la causa de su miedo en el último poema "Décima muerte". "Es la angustia de pensar / que puesto que muero existo" (Villaurrutia, 1974, p.70). El yo se expresa en este miedo y en este pensamiento. En el mismo poema, el conocimiento de la muerte como base existencial también se expresa como "conciencia": “Esta lúcida conciencia / de amar a lo nunca visto / y de esperar lo imprevisto" (p.70). El yo-lírico de Nostalgia de la muerte reacciona contra la nada externa e interna y, al estetizarla y racionalizarla, se alza sobre ella como un sujeto libre.

Para Kierkegaard, el aumento de conocimiento a través de la idea de que la nada es el centro de la existencia humana significa una mejora del autoconocimiento y la autoestima: "The law for the development of the self with respect to knowing [...] is that the increase of knowledge corresponds to the increase of self-knowledge, that the more the self knows, the more it knows itself" (Kierkegaard, 1980, p.31). Con el análisis de la ansiedad, la poesía de Villaurrutia adquiere una discursividad que tiene un efecto en la constitución del yo-lírico. Ya no se trata de un náufrago que vaga en el mar de su propia conciencia. Ahora, un sujeto seguro de sí mismo se hace presente a través del esfuerzo intelectual y discursivo. Mediante este esfuerzo comprende la causa del miedo y la expresión de la muerte y, por lo tanto, a la nada como el único absoluto. El yo se relaciona - de manera paradójica, pues dicha relación contempla a la nada como parámetro- consigo de manera consciente, confirmándose a sí mismo.

\section{La constitución dialéctica del sujeto}

En relación con Hegel, Kierkegaard propuso al hombre como el proceso de una relación de dos polos contradictorios. En Nostalgia de la muerte se puede ver un desarrollo similar al que recorre la obra de Kierkegaard: Mientras en Begrebet Angest el miedo está en el centro de la existencia del sujeto, su naturaleza es considerada, más tarde en Sygdommen til Døden, de forma dialéctica. Kierkegaard rechaza el determinismo del pensamiento sistemático; su filosofía de la espiritualidad y 
su salto de fe hacia Dios se parece más a Pascal que a los filósofos racionalistas-idealistas. Pero en la descripción de la constitución del sujeto es visible un sistema dialéctico similar al de Hegel. ${ }^{35}$

Los parámetros sobre los cuales se constituye el yo son, para Kierkegaard, los modos de la desesperación. ${ }^{36}$ Por un lado, en el sujeto existe la desesperación de ser idéntico a sí mismo. Esta desesperación se expresa en el deseo de no ser nada. En el caso de la enfermedad, por ejemplo, querer morir, pero no poder hacerlo. ${ }^{37}$ La desesperación también se puede definir como el anhelo de ser libre. Por otro lado, la vida es la desesperación de ser nada y querer ser un sujeto. ${ }^{38}$ En estos tipos de desesperación se expresa la relación base de la constitución del yo. En Nostalgia de la muerte, estas dos formas de desesperación se manifiestan, como ya se mencionó antes, con el yolírico que expresa miedo ante la nada (y quiere ser algo), pero al mismo tiempo busca la nada de la noche (y quiere ser el conocimiento del todo). Kierkegaard piensa el yo, en conexión con Hegel, como la síntesis de los factores de esa relación: Esta síntesis es también la relación de los factores "finito" e "infinito" a los que corresponde lógicamente la relación de "determinación" y "libertad". El resultado de una relación es una diferencia, algo negativo. Pero para Kierkegaard, el yo no puede ser algo negativo. Lo define, entonces, como la relación de la relación consigo mismo, que puede presentarse como un factor positivo: "If, however, the relation relates itself to itself, this relation is the positive third, and this is the self." Un yo está conformado, entonces, por la negación (relación) de la negación (relación) de su ser. Yo, presentado como positivo, es por lo tanto la relación de lo

\footnotetext{
${ }^{35}$ Para Kierkegaard, el conocimiento debe estar conectado con la vida y la realidad de la existencia personal. Por eso, el conocimiento abstracto y no-edificante es para un cristiano "broma y vanidad" (Kierkegaard, 1941, p.5).

36 "It is not a rare exception that one is in despair; no, the rare, the very rare exception is that one is not in despair" (Kierkegaard, 1941, p.21).

${ }^{37} \mathrm{O}$, como en el caso de la parábola del hijo pródigo en Los apuntes de Malte Laurids Brigge, experimentar el ser autoidéntico como limitación y querer ser libre a través de la nada. Respecto a una interpretación de la parábola en Los apuntes de Malte Laurids Brigge véase Hamburger (1970).

${ }^{38}$ Los apuntes de Malte Laurids Brigge presentan estos dos tipos de desesperación esbozados por Kierkegaard: Al comienzo, la de no ser nada y querer ser alguien. $Y$ al final, en la parábola del hijo pródigo, de ser alguien, pero querer ser nada. La parábola del hijo pródigo se puede entender, mediante una lectura kierkegaardiana del texto de Rilke, como la fórmula de toda desesperación: El hijo perdido quiere deshacerse de sí mismo, quiere anular la identidad que la sociedad le atribuye: "To despair over oneself, in despair to will to be rid of oneself, is the formula for all despair [...]" (Kierkegaard, 1941, p.56). El hijo prodigo rilkeano no quiere ser amado porque los no-amados no tienen una identidad establecida, lo que les posibilita ser todo al mismo tiempo.
} 
negativo de sí mismo con lo negativo de sí mismo. La identidad propia es, por lo tanto, la relación de lo negativo de su ser con lo negativo de su propio ser. También en Nostalgia de la muerte se relacionan dialécticamente dos negatividades - el vacío del exterior y el vacío del interior del sujeto- para constituir positivamente al yo-lírico.

El yo-lírico es un ego que se define también por su negatividad, la nada y la muerte. El anhelo de morir se encuentra expresado en la desesperación de no poder llegar, todavía, a sí mismo en dicha síntesis. Al mismo tiempo, está expresado el reconocimiento y la desesperación porque el yo camina hacia su aniquilación, hacia la nada. Las dos desesperaciones que se manifiestan en una lectura kierkegaardiana de Nostalgia de la muerte son las desesperaciones del ego por no poder llegar a los estados deseados.

El yo es, por lo tanto, su propio comportamiento respecto a estas relaciones de temporalidad y eternidad, determinación y posibilidad. Está constituido por cómo se comporta respecto a estas relaciones y cómo se refleja en ellas. El yo-lírico de Nostalgia de la muerte se relaciona consigo mismo mediante sus reflexiones sobre la nada y la muerte y, por lo tanto, se postula positivamente como sujeto. Supera su miedo y llega, mediante la reflexión, a la conclusión de que la muerte es una parte no separable de la vida; de esta forma se constituye como sujeto:

¿Y qué vida sería la de un hombre que no hubiera sentido, por una vez siquiera, la sensación precisa de la muerte,

y luego su recuerdo, y luego su nostalgia?

(Villaurrutia, 1974, p.69)

No es algo sensible que se exprese en el ahora, tampoco es algo expresado en la memoria de la historia, en la atemporalidad. El yo se establece a partir de la relación entre su determinación en el ahora y su libertad en la atemporalidad. La desesperación es, para Kierkegaard, una expresión de la incapacidad del hombre para elevar las fuerzas que trabajan en él a un nivel racional. La 
desesperación es, entonces, la no-realización de una relación que se relaciona consigo mismo. El artista (el yo-lírico de Nostalgia de la muerte) finalmente tiene éxito en este empeño. En este sentido, Nostalgia de la muerte también se puede leer como la expresión de esta hermenéutica del yo, en la cual, en el curso de la antología de poemas, el yo-lírico se entiende a sí mismo como una relación que se relaciona cada vez más claramente consigo misma.

La relación entre determinación y libertad es de gran importancia para el acto de crear (y recibir) obras de arte en general -es importante para la cuestión de qué es literatura. Como resalta Terry Eagleton en su libro sobre filosofía de la literatura The Event of Literature, (2012) la libertad humana no significa que el sujeto no posea determinantes, sino que el sujeto las elija y las adapte para su propia autoconstitución. Actuar de una forma autónoma no es desligarse de reglas, sino actuar según las propias leyes establecidas independientemente. Por eso, el arte se ha considerado y se sigue considerando como paradigma de una actividad libre. ${ }^{39}$ Mediante la libre decisión $-\mathrm{y}$ en el acto libre de escribir un poema- el yo-lírico de Nostalgia de la muerte se independiza de las determinaciones de la realidad (muerte, soledad), pero también se determina en un mundo de cosas sin sentido a través de la creación artística verbal. Se constituye como un sujeto libre. En ese sentido, y modificando una frase de Octavio Paz, el lenguaje poético vuelve habitable el mundoaun cuando este hable de un mundo inhabitable.

\section{La nada y la muerte como sustitutos de dios}

La fe en dios es el último concepto que, según Kierkegaard, conforma la base de la construcción del interior del ego humano - junto con la idea del sujeto como sujeto histórico y la convicción de que el ego es un proceso dinámico-dialéctico. Para el filósofo danés, la conciencia humana debe tener su base en una entidad transcendental que la llene. (Patios 2013, p.37). Este último concepto está

\footnotetext{
39 "That there are crippling limits to any such project in real life is clear enough, which is doubtless one reason why art has been so idealised a phenomen. Because it is less constricted by the real than we are, more radically self-costituting, it seems a peculiary pure example of an autonomy which in our case can only ever be approximate. [...] Yet the cooperative form of a poem or painting is entirely compatible with freedom, once freedom is understood positively as self-determination rather than negatively as freedom from constraint" (Eagleton, 2012, pp.141-142).
} 
completamente ausente en Nostalgia de la muerte. Villaurrutia fue un creyente toda su vida, pero solo en su primera etapa creativa se encuentran poemas con una temática divina. En Ya mi súplica es Ilanto todavía se notan los temas religiosos en la obra del poeta católico. En Nostalgia de la muerte, el Dios católico ya no se menciona.

Pero, aun así, es posible interpretar Nostalgia de la muerte en conexión con lo divino. En 1925, el filósofo jesuita y teórico literario Henri Bremond defendió, con su concepto de "poesía pura", la antigua conexión de la forma lírica con Dios. El sentido oculto e indescriptible de un poema no es alcanzable mediante la razón, sino solo a través de una intuición religiosa. Este sentido remite a un significado absoluto cuyo origen es divino y místico; "cada arte en su autonomía comparte un origen y un destino con la plegaria" (Stanton, 1998, p.129). La poesía, con su sentido velado, tiene acceso a ese origen. Para el discurso logo y fonocéntrico el acceso está vedado. En ese sentido, también el poemario de Villaurrutia señala a dicho origen divino, aunque su contenido niegue rotundamente tal significación trascendental. ${ }^{40}$

En Nostalgia de la muerte se expresa la ausencia de un dios en la libertad, en la actuación del humano "como" si él mismo fuera un dios. Es la muerte que da ese lugar analógico al humano: "Nada es el mar que como un dios quisiste poner entre los dos". Pero es la muerte la que realmente sustituye al Dios omnipresente; ${ }^{41}$ el humano libre no logra establecer distancia con ella, es una compañía constante, como lo era Dios antes. Es la única entidad que existe, ya que nada es el mar, nada la tierra, nada el tiempo y nada el sueño. Si Kierkegaard propone como base para la constitución del sujeto una entidad transcendental que es Dios, ahora esa base es una entidad metafísica negativa: la nada que es la muerte, que está envuelta - abrazada por el sujeto en los tiempos del nihilismo para constituirse, paradójicamente, como un sujeto-; es la nada que hay que

\footnotetext{
${ }^{40}$ Para George Steiner, la poesía es cercana al silencio que tiene acceso a lo divino: "Lo que está más allá de la palabra del hombre nos habla elocuentemente de Dios. Ese es el reconocimiento de la derrota dichosa que se expresa en los poemas de san Juan de la Cruz y en la tradición mística. Donde cesa la palabra del poeta comienza una gran luz" (2013, p.59).

${ }^{41}$ En las Elegías de Duino de Rilke, el dios de las primeras antologías de poemas (Libro de las imágenes, Libro de las horas) es sustituido por los ángeles.
} 
aceptar cuasi con un gesto de júbilo como base para la vida. ${ }^{42}$ Con la sustitución de Dios por la muerte y del cristianismo por el nihilismo, Villaurrutia le regresa a la muerte la importancia apriorística que le corresponde.

El filósofo y sociólogo berlinés Georg Simmel criticó, en su ensayo “Metafísica de la muerte” (1910) que el cristianismo que le quitó su significación apriorística a la muerte, poniendo la vida bajo una visión de su propia inmortalidad (Simmel, 1910, p.59). Pero la muerte no solo forma la vida en nuestra hora de morir, no solo es el paso (como predica el cristianismo) a la vida eterna, sino un aspecto fundamental de toda nuestra vida terrenal. Simmel formuló antes de Rilke y Heidegger que la muerte está conectada con la vida desde su principio y desde adentro. En ese sentido, el sujeto envuelve a la muerte como la cáscara a la fruta. ${ }^{43}$ Cada paso de la vida no solo forma un acercamiento temporal a la muerte, sino más bien, la vida está determinada por ella como un elemento real de forma positiva y a priori (Simmel, 1910, p.60). En "Nocturno en que habla la muerte" y en "Décima muerte", la muerte se vuelve de nuevo algo personal para el yo-lírico de la obra de Villaurrutia. Cuando este filosofa poéticamente sobre la muerte se trata, paradójicamente, de un filosofar sobre la esencia de la vida del sujeto. Con tal entendimiento se instala, nuevamente, la idea de una muerte personal que constituye la conciencia de cada individuo. Este concepto $-\mathrm{y}$ aquí se conecta el final de este ensayo con su principio- desapareció con el pensamiento científico positivista. Cuando en las grandes ciudades de la era moderna la muerte ya no es considerada algo personal que da identidad al sujeto, cuando morir ya no es un acto de la cotidianidad familiar, sino que está expulsada a una industria de hospitales, se convierte en lo horrible desconocido, se convierte en la nada absoluta.

\footnotetext{
${ }^{42}$ Como lo aconseja también el yo-lírico de las Elegías de Duino cuando exclama: "Wirf aus den Armen die Leere zu den Räumen hinzu, die wir atmen" (Rilke, 1991d, pp.441-442); “Arroja ya el vacío que ciñes con tus brazos / al vacío del viento que respiras" (Rilke, 2015, p.13).

${ }^{43}$ En el Libro de las horas, Rilke expresó esa idea de la muerte como una fruta de la vida de la siguiente forma: "Denn wir sind nur die Schale und das Blatt. / Der große Tod, den jeder in sich hat, / Das ist die Frucht, um die sich alles dreht" (Rilke, 1991a, p.103). "Porque nosotros somos solo la cáscara y la hoja. / La gran muerte que cada quien contiene, / es la fruta, alrededor de la cual todo gira" (La traducción es del autor de este artículo).
} 


\section{Referencias}

Adorno, T. W. (1979). Kierkegaard. Gesammelte Schriften. Tomo 2. Frankfurt a. Main: Suhrkamp.

Adorno, T. W. (1990). Standort des Erzählers im zeitgenössischen Roman. En Noten zur Literatur. Gesammelte Schriften. Tomo 11 (pp. 41-48). Frankfurt a. Main: Suhrkamp.

Alighieri, D. (1994). Die göttliche Komödie. München: Winkler.

Calderón de la Barca, P. (1989). La vida es sueño. Introducción y notas de Domingo Ynduráin. Madrid: Alianza Editorial.

Deleuze, G. (2006). El Leibniz de Deleuze. Exasperación de la filosofía. Buenos Aires: Cactus.

Drayton, M. (1908). Idea, en Daniel's Delia and Drayton's Idea (pp. 67-141). London: Eds. Arundell Esdaile, Chatto and Windus,

Eagleton, T. (2012). The Event of Literature. New Haven/London: Yale University Press.

Ficino, M. (1999). Libro del sole. En Scritti sull'astrologia (pp. 185-217). Milano: RCS Libri.

Habermas, J. (1985). Der philosophische Diskurs der Moderne. Zwölf Vorlesungen. Frankfurt a. Main: Suhrkamp.

Hegel, G. W. F. (1955). Lecciones sobre la historia de la filosofía. Tomo 3. Traducción directa por Wencelslao Roces. Ed. preparada por Elsa Cecilia Frost. México / Buenos Aires: FCE.

Hegel, G. W. F. (1979). Vorlesungen über die Geschichte der Philosophie. Werke in zwanzig Bänden. Tomo 20. Frankfurt a. Main: Suhrkamp.

Heidegger, M. (2001). ¿Qué quiere decir pensar?. En Conferencias y artículos (pp.113-126). Traducción de Eustaquio Barjau. Barcelona: Edición del Serbal.

Horn, J. Ch. (1965). Monade und Begriff - Der Weg von Leibniz zu Hegel. München: R. Oldenbourg. Jäger, W. (1942). Paideia: los ideales de la cultura griega. México: FCE.

Kierkegaard, S. (1962). The Present Age and Of the Difference Between a Genius and an Apostle.

Trad. de Alexander Dru. New York: Harper Torchbooks.

Kierkegaard, S. (1980). The Concept of Anxiety. Princeton: Princeton University Press. 
Kierkegaard, S. (2010). Postscriptum no científico y definitivo a Migajas Filosóficas. Traducción por Javier Teira y Nekane Legarreta. Salamanca: Sígueme.

Leibniz, G. (2001). Monadología. Ed. y trad. de Julián Velarde Lombraña. Madrid: Biblioteca nueva.

Maldonado, R. (2010). La conciencia de la nihilidad en la poesía de los contemporáneos. Para una hermenéutica de la muerte en la poesía mexicana. Theoría. Revista del Colegio de Filosofía, No. $20-21,95-126$.

Millares, S. (1996). Recepción del barroco hispánico en la poesía mexicana. Asociación internacional Siglo de Oro, Actas IV, 1043-1048.

Moretta, E. L. (1976). La poesía de Xavier Villaurrutia. México: FCE.

Palma, M. (2001). Presencia barroca en Xavier Villaurrutia y Elías Nandino. La Experiencia Literaria, No. 10, UNAM, 127-131.

Pascal, B. de (1897). Pensées. Paris: Léon Brunschvicg.

Pascal, B. de (1967). Pensamientos. Traducción por X. Zubiri. Madrid: Espasa-Calpe.

Patios, G. (2013). Kierkegaard's Construction of the Human Self. FORUM PHILOSOPHICUM 18, No. 1, 37-47.

Paz, O. (1986). El pliegue y sus dobles, en O. Paz (Ed.), Xavier Villaurutia. 15 poemas (pp. 3-7). México: UNAM.

Paz, O. (1989). Sor Juana Inés de la Cruz o Las trampas de la fe. Barcelona: Seix Barral.

Paz, O. (1990). Traducción: Literatura y literalidad. Barcelona: Tusquets.

Paz, O. (2003). Xavier Villaurrutia en persona y en obra. México: FCE.

Quevedo, F. de (1948). Prosa y verso. Selección y notas de Jorge Luis Borges y Adolfo Bioy Casares. Buenos Aires: Emecé.

Rilke, R. M. (1950). Briefe. Wiesbaden: Insel.

Rilke, R. M. (1991). Duineser Elegien. En Werke in drei Bänden. Tomo 1 (pp. 439-482). Frankfurt a. Main / Leipzig. Insel.

Rilke, R. M. (2015). Elegías de Duino. Duineser Elegien. Edición bilingüe. Versión de Juan Rulfo. México: Sexto Piso. 
Schnitzler, A. (1962). Das weite Land. En Die Dramatischen Werke. Tomo 2 (pp. 219-242). Frankfurt a.M.: Insel.

Shakespeare, W. (1925). Macbeth. En The Complete Works (pp. 1100-1126). New York: P.F.Collier \& Son Company.

Simmel, G. (1910). Metaphysik des Todes. LOGOS. Internationale Zeitschrift für Philosophie der Kultur, tomo I, 1910 / II, primer cuaderno (abril), 57-70.

Stanton, A. (1998). Los contemporáneos y el debate en torno a la poesía pura. En Inventores de tradición. Ensayos sobre la poesía mexicana moderna (pp. 127-147). México: Colegio de México.

Steiner, G. (2013). El silencio y el poeta. En Lenguaje y silencio (pp. 55-77). Barcelona: Gedisa

Vasconcelos, C. (1994). Dos poetas ante la muerte: Xavier Villaurrutia y Rainer Maria Rilke. En D. Rall, M. Rall (Eds.), Actas del VIII Congreso Latinoamericano de Estudios Germanísticos (pp. 263-268). México: UNAM,

Villaurrutia, X. (1974). Nostalgia de la muerte. En Obras. Poesía, Teatro, Prosas varias, Crítica (pp. 44-73). México: FCE.

Wittgenstein, L. (1967). Zettel. Ed. por G.E.M. Anscombe y G.H. von Wright, trad. por G.E.M. Anscombe. Berkeley / Los Angeles: University of California Press.

Xirau, R. (1955). Tres poetas de la soledad. México: Antigua Librería Robredo.

Weber, H. (2019). Mexikanische Literatur (1938-2018) und europäische Moderne. Berlin: Weidler Buchverlag. 